\title{
Costs of Memory: Ideas and Predictions
}

\author{
REUVEN DUKas* \\ Nebraska Behavioral Biology Group, School of Biological Sciences, \\ University of Nebraska, Lincoln, NE 68588-0118, U.S.A.
}

(Received on 3 February 1998, Accepted in revised form 19 October 1998)

\begin{abstract}
Studies on the ecology of animal memory have focused on the benefits of memory while implicitly assuming that there are costs as well. Here I discuss probable costs of memory by relying on knowledge from molecular biology and physiology, which indicates that the maintenance of accurate information in animals is an active and costly process of maintenance and repair. Redundancy probably plays a key role in ensuring a high level of accuracy; its cost is in terms of additional tissue, which increases body mass and energetic expenditure. Examining the magnitude and cost of redundancy at the neurobiological and behavioral levels can help us understand the cost of memory in particular and cognitive abilities in general.
\end{abstract}

(C) 1999 Academic Press

\section{Introduction}

The past decade has seen an accelerating number of papers addressing evolutionary and ecological aspects of cognition (see various authors in Real, 1994; Krebs \& Davies, 1997; Dukas, 1998a). Although a cost-benefit analysis is typically revealing in evolutionary ecology, most studies to date have not critically examined costs of cognitive abilities. Memory has been the focus of many recent studies. Comparative studies on memory for cached food based their predictions on the benefit of memory while implicitly assuming that memory is costly. Such investigations have found a positive correlation between dependency on cached food and spatial memory capacity in a few corvid species (Balda $\&$ Kamil, 1989), and that relative hippocampus size is larger in food storing than non-storing birds (Krebs et al., 1989; Sherry et al., 1989).

*E-mail: dukas@niko.unl.edu
This suggests that a species' memory capacity represents some trade off between benefits and costs. Otherwise, if memory were cost-free, all species could have had an equally good spatial memory.

Mathematical models of memory typically assume that memory is cost-free. Such models usually address the question of how to weigh experience and what information to forget for optimal functioning in stochastic environments (e.g. Kacelnik \& Krebs, 1985; McNamara \& Houston, 1987). Implicitly, the cost of memory in these models is in terms of using old information that has become irrelevant. Actually, such models make the simplifying assumption that information in memory must be either used or forgotten. A memory constraint widely assumed implicitly and mentioned explicitly in at least two models is a limited capacity for the amount of information that can be stored in memory (Nishimura, 1994; Belisle \& Cresswell, 1997). However, no such limitation is 
known either for humans or any other species. Moreover, at least for humans, the somewhat surprising conclusion from numerous studies is that long-term memory has essentially unlimited capacity: people that learn more, know more. Indeed, a central condition for expertise is the acquisition of vast amounts of information; human experts are more proficient and quicker in solving problems compared with novices (Larkin et al., 1980; Ericsson \& Chase, 1982; Anderson, 1983, 1990) and this indicates that storing more information in memory can increase rather than diminish performance. The ecological cost of possessing such vast memory has not been well evaluated.

A mature research program on the evolutionary ecology of information processing must be able to address costs of cognitive abilities such as memory. It is thus crucial to generate and test predictions on cognitive costs. To this end, I provide a preliminary analysis of memory costs, which relies on analogies from a few better studied systems in molecular biology and physiology. Although I focus here on memory, many of my arguments are also relevant for other cognitive and physiological capacities.

\section{Accuracy of Genetic and Neuronal Information}

For a few reasons, examining how genetic information is maintained can help us understand memory maintenance and its associated costs. First, there is general similarity between genes and neuronal memory in that both the genetic regulation of physiological activity and the neuronal control of behavior involve coordinated networks of individual units with no central control. Furthermore, a unit (gene or neuron) may belong to several networks controlling distinct functions; this feature is referred to as pleiotropy in genetics, and parallel distributed processes (PDP) in cognitive science (e.g. Wu et al., 1994; McAdams \& Shapiro, 1995; Fuster, 1997). Second, the maintenance of genetic information has been subjected to extensive research, which has uncovered general principles that may be common to other systems of information storage and processing in animals (e.g. Kirkwood et al., 1986; Bernstein \& Bernstein, 1991). Third, learning and memory involve gene expression that alter neuronal properties (e.g. Dudai, 1989; Mayford et al., 1995; Tully, 1996; Yin \& Tully, 1996; Abel et al., 1998). Hence some mechanisms of memory maintenance are directly linked to information maintenance at the genetic level. The following discussion will rely on the general similarity between genetic and neuronal information systems. No attempt will be made to relate a specific unit in one system to a unit in the other.

\section{MAINTENANCE AND REPLICATION OF DNA}

Living cells must accurately maintain genetic information for long periods of time. That maintenance is not a passive process because the rate of DNA damage is very high. For example, a typical mammalian cell experiences tens of thousands of DNA damages per day. If such damages remain unrepaired, they interfere with DNA replication and gene transcription (Bernstein \& Bernstein, 1991; Avise, 1993). In other words, genetic information cannot simply be stored and remain error-free. Rather, errors are generated frequently and must be corrected through active error correction mechanisms. The genetic information is also replicated frequently and this process also is error-prone requiring corrections. Some of the error correction mechanisms rely on the redundancy inherent in the basic double-strand structure of DNA. This implies, for example, that single-strand damage, which is quite common, can readily be corrected by using the redundant information in the complementary strand as a template (e.g. Bernstein \& Bernstein, 1991).

In addition to accurately maintaining and replicating genetic information, it must be ensured that only relevant information is expressed. For two reasons, the expression of relevant information must also involve active control of accuracy. First, at any given time, the majority of genes in each cell are supposed to be inactive. In reality, however, that inactivity is imperfect, meaning that a small proportion of "silent" genes produce unscheduled transcripts that could potentially interfere with normal cell functioning (Chelly et al., 1989; Bird, 1995). Second, even if only relevant information is expressed, the simultaneous transmission of numerous messages can create noise, which may 
cause error in interpreting each individual message. For example, parts of one message may erroneously be mixed with another message similar in structure. Because many biological systems share identical symbols, such as enzymes, hormones and cyclic AMP, error in message interpretation is quite feasible (Regal, 1977).

\section{TRANSFER AND MAINTENANCE OF MEMORY}

Once a new item of memory has been acquired, it undergoes a process of transfer, or consolidation, from short- into long-term memory. This implies that information has to be transferred from one system of temporary storage into another system that can retain that information for a long time (e.g. Dudai, 1989; Goelet et al., 1986; Fuster, 1995; McClelland et al., 1995; Tully, 1996). That information transfer is somewhat similar to replication or transcription of genetic information. As with genetic information, the transition from short- to long-term memory probably involves error, which may be corrected with some cost. Once in long-term memory, an item has to be maintained, perhaps for a long time. Unlike genetic information, however, some memories can be altered over time; this means that such memories must be maintained in somewhat plastic form, which allows change but may also be more susceptible to error. Finally, at any given time, most of the information in long-term memory is inactive. This implies that there must be a mechanism that allows accurate silencing of irrelevant information and correct interpretation of neuronal messages in a noisy environment as it is with genetic information.

There are probably two classes of mechanisms that control accuracy of memories. The first type of processes must ensure a certain level of accuracy at the genetic and cellular level of neurons in manners similar to any other type of cell. Such general mechanisms are partially understood; it is even known that DNA damage occurs in neural tissue as it does in any other tissue, and that such damage accumulates with age (Bernstein \& Bernstein, 1991, p. 48). The other class of mechanisms has to ensure accuracy at the network level, where neural representation of information requires coordination among numerous cells, where each cell may belong to a few distinct networks that hold different items of information (e.g. Squire et al., 1991; Thompson \& Krupa, 1994; Wu et al., 1994). The coordination of a neural network is somewhat analogous to the organization of embryonic cells during development and differentiation. The fact that cells containing identical genetic information have different phenotypes implies that they express only a small fraction of their genomes. The decision of what genes to express depends on cells' positions in the early embryo and on some kind of inter-cell information system (Galas et al., 1986). Similarly, individual neurons must determine their exact associations with other neurons and maintain the established pattern of organization for a long time.

\section{The Cost of Accurate Information}

\section{THE COST OF GENETIC ACCURACY AND ITS OPTIMAL} LEVEL

A few mechanisms ensure high levels of accuracy of genetic information and numerous enzymatic processes exist to repair routine damage and errors generated during replication (reviewed by Kirkwood et al., 1986; Bernstein \& Bernstein, 1991). The production and maintenance of these enzymes incur energetic and nutritional costs. However, perhaps the most significant cost of accuracy is the need to maintain redundancy, which is probably the simplest way to recover information lost due to DNA damage. The maintenance of redundant information implies an overall increase in the volume of information stored, with its attendant higher cost of tissue production, maintenance, repair, and replication.

The accurate maintenance of genes' inactivity appears to involve DNA methylation (Bird, 1995). Again, this mechanism and its regular maintenance probably involves expenditure of energy and nutrients. Two ways of reducing error in message interpretation are, first, temporal redundancy, meaning repetition of the same message several times to ensure correct interpretation by the receiver. Besides the energetic cost of such redundancy, it also reduces speed of operation. Another way of reducing 
error in message interpretation is the reduction of information transfer through elimination of less essential features (Regal, 1977). This can be achieved through permanent evolutionary loss (e.g. lack of eyes in cave animals) or phenotypic plasticity, which allows time- or space-dependent expression of certain features.

Research on the action of various forms of DNA polymerase from phage T4 illustrates the cost of accuracy. First, an increase in the accuracy of DNA polymerase results in an exponential increase in energetic expenditure. Second, the increase in accuracy is also accompanied with a decrease in overall speed of DNA synthesis. Probably the most notable observation is that wild-type polymerase is significantly less accurate than it could become by acquiring certain mutations (Bessman et al., 1974; Galas \& Branscomb, 1978). This suggests that the regulation of genetic accuracy in that organism depicts a balance between the attendant benefits and costs in terms of resources otherwise directed to other functions affecting fitness (Galas et al., 1986). Similarly, it has been shown that for sexual organisms, lifetime fitness is maximized when the investment in maintenance and repair is lower than the level that assures perfect restoration. The consequence of such optimal but imperfect repair is senescence (Kirkwood \& Holliday, 1986; Bernstein \& Bernstein, 1991; Kirkwood \& Rose, 1991; Rose, 1991; Denis \& Lacroix, 1993).

\section{THE COST OF ACCURATE MEMORY AND ITS OPTIMAL}

\section{LEVEL}

The maintenance of accurate memories is probably costly. First, there must exist physiological processes that control accurate transfer of information, repair, and silencing of irrelevant memories. Such processes have not yet been subjected to intensive research. Second, to ensure reliable repair, and because repair cannot be perfect, substantial redundancy may be necessary. Although it is accepted that redundancy exists in the brain, it is still unclear what its exact magnitude is (Glassman, 1987; Bernstein \& Bernstein, 1991); neither is it known how redundant information is coordinated to ensure maintenance of crucial memories when either individual cells or a whole neural network fail.
As with genetic information, the degree of accuracy of memories over time should reflect some balance between costs and benefits. For example, theory suggests that asexual organisms should invest much more than sexual ones in maintenance and repair of DNA. Thus asexual organisms should show little or no senescence, a prediction that seems to be supported by current evidence (Rose, 1991). Similarly, within the brain, different classes of memory may undergo different schedules of maintenance and repair depending on their expected relevance. That is, memories with potentially small effects on fitness may show rapid decay while more important ones, which are better maintained and/or more redundant, may not be forgotten. It appears that animals can determine the importance of certain information through proximate mechanisms of emotion.

Extensive research on the amygdala indicates that this brain structure controls emotional memories (e.g. fear conditioning) through a specialized physiological system (e.g. Davis, 1992; Cahill et al., 1994, 1995; LeDoux, 1995; Cahill \& McGaugh, 1996; McGaugh et al., 1996). In other words, it seems that the brain can determine the fitness values of certain events through proximate emotional mechanisms (Cabanac, 1992) and then classify events into a certain memory category, which may have a category-specific retention period. It is indeed known that conditioned fear reactions are remembered for very long periods and that they are very difficult to extinguish (LeDoux, 1995, p. 219). This suggests that such memories, which may have strong fitness consequences, are subjected to different physiological processes than less important memories. It is also possible that a tradeoff involved in generating a long-lasting memory is a lesser ability to lose it even if the relevant conditions change.

Indirect evidence from primates suggests that different classes of memory are maintained in distinct ways which affect probability of recall. Semantic memory (general and gradually learned information about events, habits and skills) is more resistant to brain damage and more available to retrieval than episodic memory (specific and rapidly acquired information about time and place events; see Tulving, 1985; Sherry 
\& Schacter, 1987; Squire et al., 1993). The reason for this difference in probability of recall is probably that semantic memory is determined by multiple associations in numerous neural networks, which have more lines of associative access than the more specific episodic networks (Fuster, 1995, p. 216). This is similar to the idea that sufficient redundancy can ensure accurate maintenance of important information. In general, the idea that there is a biological need for maintaining several systems of memory has been discussed extensively (Sherry \& Schacter, 1987; Shettleworth, 1993). Here I extend this notion to address the issue of memory costs.

Although the accurate silencing of inactive memories has not been studied in detail, it is known that interference between items in memory does occur; this means that learning new information can interfere with recall of old information (retroactive interference), and old memories may interfere with the acquisition of new information (proactive interference) (reviewed by Spear \& Riccio, 1994; Anderson, 1995). Several studies have addressed memory interference in insects and warm blooded animals (Stanton, 1983; Lewis, 1986; Woodward \& Laverty, 1992; Clayton \& Krebs, 1994a; Goulson et al., 1997; Gegear \& Laverty, 1998); and in birds and mammals, the hippocampus has been suggested to play a role in reducing interference (Shapiro \& Olton, 1994; Hampton \& Shettleworth, 1996). Further research is necessary in order to establish the fitness cost of memory interference of animals engaging in relevant tasks requiring a high memory load.

One way of decreasing memory interference is through reduction of information storage and transfer. This can be achieved through either selective acquisition of information or elimination of less essential memories. That is, if interference indeed has substantial fitness cost, it may be optimal to eliminate memories with small fitness contribution and thereby increase the overall accuracy of information storage and usage. This can be achieved through not learning at all certain information, learning only a part of the available information, or selective elimination of memories at some regular interval. At the broader ecological scale, memory interference may be one factor selecting for short- or long-term diet specialization, a feature common to many animals (Dukas \& Ellner, 1993; Bernays \& Wcislo, 1994; Dukas \& Clark, 1995; Bernays, 1998; Dukas, 1998b).

EVALUATING THE COST OF ADDITIONAL BRAIN TISSUE

In the preceding section I mentioned two possible types of memory cost: (i) a larger brain or brain component due to redundancy, with the associated increased energetic and nutritional costs, and (ii) interference. Between the two possible types of memory cost, redundancy may consist the most significant yet least studied cost. It is indeed known that there is a positive correlation between reliance on spatial memory and hippocampus size in a few groups of birds (e.g. Krebs et al., 1989; Sherry et al., 1989; Sherry, 1998) and that an individual's experience with food storing is positively correlated with hippocampus size (Clayton \& Krebs, 1994b, 1995); but it is not yet established what the function of extra hippocampal tissue is. Many other studies have documented a positive correlation between some cognitive ability and volume of the whole or part of the brain (e.g. Eisenberg \& Wilson, 1978; Clutton-Brock \& Harvey, 1980; Harvey \& Krebs, 1990; Healy \& Guilford, 1990; Lefebvre et al., 1997), although that issue is still under debate and further investigation. It is fair to assume that one function of extra brain volume is redundancy (see Predictions section below), but the following discussion will only rely on the currently agreed notion that enhanced memory ability is associated with a larger volume of a brain part. The central question then is whether possessing a brain component or a whole brain larger by a few percent is costly. Currently, this question can be answered only somewhat indirectly, through the examination of costs of other types of body tissue.

Some insect species have flight capable and flightless morphs, the latter have flight muscles reduced by about $50 \%$, which is $5-10 \%$ of their whole body mass. In these insects there is a strong negative correlation between flight muscle mass and ovarian mass and its consequent egg production rate (Zera \& Denno, 1997). Experimental manipulation of flight muscle mass through application of juvenile hormone in 
crickets reveals that, depending on the quality of available food, flightless crickets possess ovaries with 2-4 times the mass of flight capable crickets. Flightless individuals have reduced respiration and reduced levels of lipid and triglycerides (flight fuel) stores; this suggests that the increased allocation of nutrients to ovarian growth in the flightless crickets results from reduced direct and indirect energetic costs of flight muscle maintenance (Zera et al., 1998).

In birds and mammals, muscles show rapid atrophy when unexercised and hypertrophy when workload is increased (Gordon, 1967; Gaunt et al., 1990; Piersma \& Lindstrom, 1997). Birds even show a diurnal variation in mass due to the possession of a larger fat storage at dusk. Metcalf \& Ure (1995) found that zebra finches were $7 \%$ heavier and over $30 \%$ slower in flight maneuvering at dusk than at dawn; this may translate into up to $70 \%$ greater risk of predation (Bednekoff, 1996, see also Witter et al., 1994). Finally, in thoroughbred horse racing, the effect of extra loads is well documented and is commonly used to equalize horse performance. A rule of thumb among racers is that a load difference of about $0.3 \%$ body mass is sufficient to cause a one-body-length change in the finish for otherwise equally matched horses (Scott, 1968).

In sum, experimental evidence indicates that even a very small addition of up to a few percent of body mass can have significant fitness consequences due to (1) increased energetic and nutritional requirements (Zera et al., 1998), which are especially high for brain tissue (e.g. Hawkins, 1985), and (2) decreased maneuverability associated with increased body mass (Metcalf \& Ure, 1995). This can explain the widespread phenomenon of plasticity in organ size and the rapid evolutionary loss of useless features. The temporary or long-term loss of a part of or whole body component may translate into a lighter body with the consequent saving in energy expenditure and decreased predation risk. Alternatively, due to various alometric or developmental constrains (e.g. Maynard Smith et al., 1985), the size of an organ such as the brain may remain constant, but the lost tissue will be replaced with another one with higher utility. The latter seems to be the case in the blind mole rat, where the cortex area typically devoted to vision has been substituted with neurons devoted to processing of somato-sensory information (Cooper et al., 1993; Diamond, 1996; Nevo, 1998).

\section{Predictions}

There are a few non-mutually exclusive ways to create redundancy. First, one can possess a few copies of the same information. Second, one can initially retain more details of a scene than is necessary for recall. This way, if some information is lost, recall is still possible. For example, if remembering three out of six landmarks is sufficient to locate a cache, a minimalist strategy will be storing in memory three landmarks only with some probability of losing that information due to partial forgetting. By contrast, the maximal alternative of recording all six landmarks may require more storage tissue but will substantially reduce probability of information loss in case of partial forgetting. If the above example is correct, one may find that a bird species that relies more heavily on cached food memorizes a larger number of landmarks associated with a cache than a closely related species less dependent on caches. Finally, another way of creating redundancy is by extracting additional information through some higher level processing or association with other information already in memory. For example, one may locate a food cache based on the memory that it is $x \mathrm{~cm}$ from landmark $a$ and $y \mathrm{~cm}$ from landmark $b$. An additional redundant information may be that the cache is, for example, twice as close to $a$ as $b$, or that the spatial orientation of that cache and landmarks is identical to some other food caches of that individual (see Kamil \& Jones, 1997). This kind of higher level processing would probably require additional specialized neural tissue. If this example is correct, one may find that a bird species that relies more heavily on cached food is able to acquire a broader variety of information associated with a cache than a closely related species less dependent on caches.

The general question whether more neurons are involved in memorizing a specific task may be addressed by some method of brain imaging. 
There has been rapid increase in the spatial and temporal resolution of brain imaging (Barinaga, 1997) and it has recently been applied to birds as well (Romangnano et al., 1996). Additional neurobiological study can reveal the exact function of the neuronal centers involved. Comparative behavioral experiments can reveal whether enhanced memory results from memorizing more details or some higher level processing. For example, to quantify the resolution of memory, one can compare closely related species such as seed caching corvids (Balda et al., 1996) for their abilities to distinguish between pairs of images varying in their details and similarities (see Gould, 1987). Similarly, one can compare such bird species for their abilities to recover caches at the presence of only a proportion of the landmarks originally occurring at the time of caching. It is feasible that species that rely more heavily on cached food would show finer resolution of spatial memory for caches and better ability to find caches after some landmarks have been removed.

The cost of brain tissue can also be evaluated experimentally. In some birds, there is seasonal variation in the volumes of brain components such as the song nucleus (Nottebohm, 1981) and hippocampus (Smulders et al., 1995). Specific experiences can also affect the volumes of these brain parts (Clayton \& Krebs, 1994b; Healy et al., 1996). So one can experimentally create through manipulation of day length or experience groups of birds with different volumes of brain components and then compare overall brain volumes, energy expenditure and other physiological parameters (see Hawkins, 1985). Similarly, experience has strong effects on mushroom body size in fruit flies (Heisenberg et al., 1995; Barth \& Heisenberg, 1997); the genes determining mushroom body size have been identified as well (deBelle \& Heisenberg, 1996). Hence this model system can also be employed for an experimental evaluation of the cost of brain tissue. It is likely that under controlled laboratory conditions, reduced brain size in the flies would translate into increased reproductive rate.

Among the few possible costs of memory, redundancy and its associated physiological cost is the issue in greatest need of evaluation because no current information on this topic is available. It is feasible, however, that many species suffer from interference or reduced speed of information processing with increased memory load. Several experimental methods to evaluate effects of interference in field or controlled semi-natural conditions exist (e.g. Stanton, 1983; Lewis, 1986; Dukas, 1995; Hampton \& Shettleworth, 1996; Goulson et al., 1997; Gegear \& Laverty, 1998) and I thus do not elaborate on this topic further. Preliminary experiments with grasshoppers suggest that individuals with a broader diet require longer time to choose a food type for their next meal (Bernays, 1998). This intriguing data, which suggests that more information in memory reduces the rate of information processsing, can be substantiated using methods similar to Bernays', of experimentally creating foragers with distinct diet breadth.

In sum, I employed the elaborate literature on genetic information to argue that a biological information system such as memory is prone to error and hence, is in need of active maintenance, and redundancy, which allows recovery of crucial information. Memories crucial for survival and reproduction probably require substantial redundancy, which entails costs through increased body mass that decreases maneuverability and increases energy expenditure. The level and type of redundancy in memory can be studied through behavioral experiments and direct neurobiological measurements.

I thank A. Brodin, C. Clark, L. Gass, B. Gibson, D. Grunbaum, A. Kamil, T. Zera and two anonymous referees for helpful discussions and comments. My research has been supported by NIH grant MH57282-01.

\section{REFERENCES}

Abel, T., Martin, K. C., Bartch, D. \& Kandel, E. R. (1998). Memory suppressor genes: inhibitory constraints on the storage of long-term memory. Science 279, 338-341.

ANDERSON, J. R. (1983). Retrieval of information from long-term memory. Science 220, 25-30.

Anderson, J. R. (1990). Cognitive Psychology and its Implications. New York: Freeman.

Anderson, J. R. (1995). Learning and Memory. New York: Wiley.

BAlDA, R. P. \& Kamil, A. C. (1989). A comparative study of cache recovery by three corvid species. Anim. Behav. 38, 486-495. 
BARINAGA, M. (1997). New imaging methods provide a better view into the brain. Science 276, 1974-1977.

BARTh, M. \& HeisenberG, M. (1997). Vision affects muchroom bodies and central complex in Drosophila melanogaster. Learning \& Memory 4, 219-229.

BeDneKofF, P. A. (1996). Translating mass dependent flight performance into predation risk: an extension of Metcalfe \& Ure. Proc. R. Soc. Lond. B 263, 887-889.

Belisle, C. \& CResswell, J. (1997). The effects of a limited memory capacity on foraging behavior. Theor. Popul. Biol. 52, 78-90.

Bernays, E. A. (1998). The value of being a resource specialist: behavioral support for a neural hypothesis. Am. Natur. 151, 451-464.

Bernays, E. A. \& Wcislo, W. T. (1994). Sensory capabilities, information processing, and resource specialization. Quart. Rev. Biol. 69, 187-204.

Bernstein, C. \& Bernstein, H. (1991). Aging, Sex, and DNA Repair. San Diego: Academic Press.

Bessman, A. N., MuzyczKa, N., Goodman, M. \& Schnaar, R. (1974). Studies on the biochemical basis of spontaneous mutation. II The incorporation of a base and its analogue into DNA by wild-type, mutator, and anti-mutator DNA polymerase. J. Mol. Biol. 88, 409-421.

BIRD, A. P. (1995). Gene number, noise reduction and biological complexity. Trends Gen. 11, 94-100.

Cabanac, M. (1992). Pleasure: the common currency. $J$. theor. Biol. 155, 173-200.

Cahill, L. \& McGaugh, J. L. (1996). Modulation of memory storage. Curr. Opin. Neurobiol. 6, 237-242.

Cahill, L., Babinski, R., Markowitsch, H. J. \& McGaugh, J. L. (1995). The amygdala and emotional memory. Nature 377, 295-296.

Cahill, L., Prins, B., Weber, M. \& McGaugh, J. L. (1994). b-Adrenergic activation and memory for emotional events. Nature 371, 702-704.

Chelly, J., Concordet, J. P., Kaplan, J. C. \& Kahn, A. (1989). Illegitimate transcription: transcription of any gene in any cell type. Proc. Nat. Acad. Sci. U.S.A. 86, 2617-2621.

Clayton, N. S. \& Krebs, J. R. (1994a). One-trial associative memory: comparisons of food-storing and nonstoring species of birds. Anim. Learn. \& Behav. 22, 366-372.

Clayton, N. S. \& Krebs, J. R. (1994b). Hippocampal growth and attrition in birds affected by experience. Proc. Nat. Acad. Sci. U.S.A. 91, 7410-7414.

Clayton, N. S. \& Krebs, J. R. (1995). Memory in food-storing birds: from behaviour to brain. Curr. Opin. Neurobiol. 5, 149-154.

Clutton-Brock, T. H. \& Harvey, P. H. (1980). Primates, brains and ecology. J. Zool. 190, 309-323.

Cooper, H. M., Herbin, M. \& Nevo, E. (1993). Ocular regression conceals adaptive progression of the visual system in a blind subterranean mammal. Nature 361, $156-159$.

DAVIS, M. (1992). The role of the amygdala in fear and anxiety. Ann. Rev. Neurosci. 15, 353-375.

de Belle, J. S. \& Heisenberg, M. (1996). Expression of Drosophila mushroom body mutations in alternative genetic backgrounds: a case study of the mushroom body miniature gene (mbm). Proc. Nat. Acad. Sci. U.S.A. 93, 9875-9880.

Denis, H. \& Lacroix, J. C. (1993). The dichotomy between germ line and somatic line, and the origin of cell mortality. Trends Gen. 9, 7-11.

Diamond, J. M. (1996). Competition for brain space. Nature (London) 382, 756-757.

DudAI, Y. (1989). The Neurobiology of Memory: Concepts, Findings, Trends. Oxford: Oxford University Press.

DukAs, R. (1995). Transfer and interference in bumblebee learning. Anim. Behav. 49, 1481-1490.

DukAs, R. (1998a). Cognitive Ecology: The Evolutionary Ecology of Information Processing and Decision Making. Chicago: University of Chicago Press.

DuKas, R. (1998b). Constraints on information processing and their effects on behavior. In: Cognitive Ecology (Dukas, R., ed.) pp. 89-127. Chicago: University of Chicago Press.

Dukas, R. \& Clark, C. W. (1995). Searching for cryptic prey: a dynamic model. Ecology 76, 1320-1326.

DUKAS, R. \& ElLnER, S. (1993). Information processing and prey detection. Ecology 74, 1337-1346.

EISENBERG, J. F. \& Wilson, D. E. (1978). Relative brain size and feeding strategies in the Chiroptera. Evolution 32, $740-751$.

Ericsson, K. A. \& Chase, W. G. (1982). Exceptional memory. Am. Sci. 70, 607-615.

Fuster, J. M. (1995). Memory in the Cerebral Cortex. Cambridge, MA: MIT Press.

Fuster, J. M. (1997). Network memory. Trends Neurosci. 20, 451-459.

Galas, D. J. \& Branscomb, E. (1978). The enzymatic determination of DNA polymerization acuracy: theory of T4 polymerase mechanisms. J. Mol. Biol. 124, 653-687.

Gaunt, A. S., Hikida, R. S., Jehl, J. R. \& Fenbert, L. (1990). Rapid atrophy and hypertrophy of an avian flight muscle. Auk 107, 649-659.

Gegear, R. J. \& Laverty, T. M. (1998). How many flower types can bumblebees forage on at the same time?

Glassman, R. B. (1987). An hypothesis about redundancy and reliability in the brains of higher species: analogies with genes, internal organs, and engineering systems. Neurosci. Behav. Rev. 11, 275-285.

Goelet, P., Castellucci, V. F., Schacher, S. \& Kandel, E. R. (1986). The long and the short of long-term memory-a molecular framework. Nature 322, 419-422.

Gordon, E. E. (1967). Anatomical and biochemical adaptations of muscle to different exercise. J. Am. Med. Assoc. 201, 129-132.

Gould, J. L. (1987). Landmark learning by honey bees. Anim. Behav. 35, 26-34.

Goulson, D., Stout, J. C. \& Hawson, S. A. (1997). Can flower constancy in nectaring butterflies be explained by Darwin's interference hypothesis? Oecologia 112, 225-231.

Hampton, R. R. \& Shettleworth, S. J. (1996). Hippocampus and memory in a food-storing and in a non-storing bird species. Behav. Neurosci. 110, 946-964.

Harvey, P. H. \& Krebs, J. R. (1990). Comparing brains. Science 249, 140-146.

Hawkins, R. (1985). Cerebral energy metabolism. In: Cerebral Energy Metabolism and Metabolic Encephalopathy (McCandless, D. W., ed.) pp. 3-23. New York: Plenum Press.

Healy, S. D. \& Guilford, T. (1990). Olfactory bulb size and nocturnality in birds. Evolution 44, 339-346. 
Healy, S., Gwinner, E. \& Krebs, J. (1996). Hippocampal volume in migratory and non-migratory warblers: effects of age and experience. Behav. Brain Res. 81, 61-68.

Heisenberg, M., Heusipp, M. \& Wanke, C. (1995). Structural plasticity in the Drosophila brain. J. Neurosci. 15, 1951-1960.

KACELNIK, A. \& KreBs, J. R. (1985). Learning to exploit patchily distributed food. In: Behavioural Ecology (Sibly, R. M. \& Smith, R. H., eds) pp. 189-205. Oxford: Blackwell.

Kamil, A. C. \& Jones, J. E. (1997). The seed-storing corvid Clark's nutcracker learns geometric relationships among landmarks. Nature 390, 276-279.

Kirkwood, T. B. L. \& Holliday, R. (1986). Selection for optimal accuracy and the evolution of ageing. In: Accuracy in Molecular Processes (Kirkwood, T. B. L., Rosenberger, R. F. \& Galas, D. J., eds) pp. 363-379. London: Chapman \& Hall.

Kirkwood, T. B. L. \& Rose, M. R. (1991). Evolution of senescence: late survival sacrificed for reproduction. Phil. Trans. R. Soc. Lond. B 332, 15-24.

Kirkwood, T. B. L., Rosenberger, R. J. \& Galas, D. J. (1986). Accuracy in Molecular Processes. London: Chapman \& Hall.

Krebs, J. R. \& Davies, N. B. (1997). Behavioural Ecology. Oxford: Blackwell.

Krebs, J. R., Sherry, D. F., Healy, S. D., Perry, V. H. \& VACCARINO, A. L. (1989). Hippocampal specialization in food-storing birds. Proc. Nat. Acad. Sci. U.S.A. 86, 1388-1392.

Larkin, J., McDermont, J., Simon, D. P. \& Simon, H. A. (1980). Expert and novice performance in solving physics problems. Science 208, 1335-1342.

LeDoux, J. E. (1995). Emotion: clues from the brain. Annu. Rev. Psychol. 46, 209-235.

Lefebvre, L., Whittle, P., Lascaris, E. \& Finkelstein, A. (1997). Feeding innovations and forebrain size in birds. Anim. Behav. 53, 549-560.

LEWIS, C. A. (1986). Memory constraints and flower choice in Pieris rapae. Science 232, 863-865.

Mayford, M., Abel, T.\& Kandel, E. R. (1995). Transgenic approaches to cognition. Curr. Opin. Neurobiol. 5, 141-148.

Maynard Smith, J. R., Burian, R., Kauffman, S., Alberch, P., Campbell, J., Goowin, B., LAnde, R., Raup, D. \& WolPerT, L. (1985). Developmental constraints and evolution. Quart. Rev. Biol. 60, 265-287.

McAdams, H. H. \& Shapiro, L. (1995). Circuit simulation of genetic networks. Science 269, 650-656.

McClelland, J. L., McNaughton, B. L. \& O'Reilly, R. C. (1995). Why there are complementary learning systems in the hippocampus and neocortex: insights from the successes and failures of connectionist models of learning and memory. Psych. Rev. 102, 419-457.

McGaugh, J. L., Cahill, L. \& Roozendaal, B. (1996). Involvement of the amygdala in memory storage: interaction with other brain systems. Proc. Nat. Acad. Sci. U.S.A. 93, 13508-13514.

McNamara, J. M. \& Houston, A. I. (1987). Memory and the efficient use of information. J. theor. Biol. 125, 385-395.

Metcalfe, N. B. \& Ure, S. E. (1995). Diurnal variation in flight performance and hence potential predation risk in small birds. Proc. R. Soc. Lond. B 261, 395-400.
Nevo, E. (1998). Evolution of a visual system for life without light: optimization via tinkering in blind mole rats. In: Principles of Animal Design (Weibel, E. R., Taylor, C. R. \& Bolis, L., eds). Cambridge: Cambridge University Press.

Nichimura, K. (1994). Decision making of a sit-and-wait forager in an uncertain environment: learning and memory load. Am. Nat. 143, 656-676.

Notтевонм, F. (1981). A brain for all seasons: cyclical anatomical changes in song-control nuclei of the canary brain. Science 214, 1368-1370.

Piersma, T. \& Lindstrom, A. (1997). Rapid reversible changes in organ size as a component of adaptive behaviour. Trends Ecol. Evol. 12, 134-138.

REAL, L. A. (1994). Behavioral Mechanisms in Evolutionary Ecology. Chicago: University of Chicago Press.

REgal, P. J. (1977). Evolutionary loss of useless features: is it molecular noise supression. Am. Nat. 111, $123-133$.

Romagnano, A., Shiroma, J. T., Heard, D. J., Johnson, R. D., Schiering, M. R. \& Mladinich, C. R. J. (1996). Magnetic resonance imaging of the brain and coelomic cavity of the domestic pigeon (Columbia livia domestica). Vet. Radio. \& Ultras. 37, 431-440.

Rose, M. R. (1991). Evolutionary Biology of Aging. New York: Oxford University Press.

Scott, B. (1968). The Racing Game. Chicago: Aldine.

Shapiro, M. L. \& Olton, D. S. (1994). Hippocampal function and interference. In: Memory Systems 1994 (Schacter, D. L. \& Tulving, E., eds). Cambridge, MA: MIT Press.

SHERRY, D. F. (1998). The Ecology and neurobiology of spatial memory. In: Cognitive Ecology: The Evolutionary Ecology of Information Processing and Decision Making (Dukas, R., ed.). Chicago: University of Chicago Press.

Sherry, D. F. \& Schacter, D. L. (1987). the evolution of multiple memory systems. Psych. Rev. 94, 439-454.

Sherry, D. F., Vaccarino, A. L., Buckenham, K. \& Herz, R. S. (1989). The hippocampal complex of food-storing birds. Brain, Behav. Evol. 34, 308-317.

Shettleworth, S. J. (1993). Varieties of learning and memory in animals. J. Exp. Psych: Anim. Behav. Proc. 19, 5-14.

Smulders, T. V., Sasson, A. D. \& DeVoogd, T. J. (1995). Seasonal variation in hippocampal volume in a food-storing bird, the black-capped chickadee. $J$. Neurobiol. 27, 15-25.

Spear, E. N. \& Riccio, D. C. (1994). Memory: Phenomena and Principles. Boston: Allyn \& Bacon.

Squire, L. R., Weinberger, N. M., Lynch, G. \& McGaugh, J. L. (1991). Memory: Organization and Locus of Change. New York: Oxford University Press.

Squire, L. R., Knowlton, B. \& Musen, G. (1993). The structure and organization of memory. Annu. Rev. Psychol. 44, 453-495.

Stanton, M. L. (1983). Short-term learning and the searching acuracy of egg-laying butterflies. Anim. Behav. 31, 33-40.

Thompson, R. F. \& Krupa, D. J. (1994). Organization of memory traces in the mammalian brain. Ann. Rev. Neurosci. 17, 519-549.

Tully, T. (1996). Discovery of genes involved with learning and memory: an experimental synthesis of Hirschian and Benzerian perspectives. Proc. Nat. Acad. Sci. U.S.A. 93, 13460-13467. 
Witter, M. S., Cuthill, I. S. \& Bonser, R. H. C. (1994). Experimental investigation of mass-dependent predation risk in the European starling, Sturnus vulgaris. Anim. Behav. 48, 201-222.

WOODWARD, G. \& LAVERTY, T. M. (1992). Recall of flower handling skills by bumble bees: a test of Darwin's interference hypothesis. Anim. Behav. 44, 1045-1051.

Wu, J. Y., Cohen, L. B. \& FalK, C. X. (1994). Neuronal activity during different behaviors in Aplysia: a distributed organization. Science 263, 820-822.
YIN, J. C. P. \& TUlly, T. (1996). CREB and the formation of long-term memory. Curr. Opin. Neurobiol. 6, 264-268.

Zera, A. J. \& Denno, R. F. (1997). Physiology and ecology of dispersal polymorphism in insects. Ann. Rev. Ent. 42, 207-230.

Zera, A. J., Potts, J. \& Kobus, K. (1998). The physiology of life-history trade-offs: experimental analysis of a hormonally-engineered life-history trade-off in Gryllus assimilis. Am. Nat. 152, 7-23. 